\title{
Are Clinical Features and Severity Vital While Deciding the Treatment in Sleep Apnea Syndrome?
}

\author{
Ahmet Cemal Pazarlı $\cdot$ Mehmet Akif Abakay ${ }^{2} \cdot$ Timur Ekiz $^{3}$ \\ Departments of ${ }^{I}$ Chest Diseases, ${ }^{2}$ Otorhinolaryngology, and ${ }^{3}$ Physical and Rehabilitation Medicine, Elbistan State Hospital, \\ Kahramanmaraş, Turkey
}

To the editor:

We have taken great interest in the recently published article entitled "Five-Year Subjective Outcomes of Obstructive Sleep Apnea Surgery: A Multi-Institutional Study" by Choi et al. [1]. Authors have studied, five-year subjective outcomes of obstructive sleep apnea surgery. However, we have some drawbacks for the aforementioned article.

First, the text lacks of the clinical and demographical features of the subjects. The authors had better clarify how they evaluated the patients? Did they perform sleep endoscopy? Which patients did receive surgical treatment or positive airway pressure? Which patients were included in the control group? We believe that this item is vital as regards the clinical relevance of this study because the readers could understand the groups clearly and comment for their clinical experience. Second, the authors did not classify the patients with respect to the severity (mild, moderate, or severe) of sleep apnea syndrome. Severity of the sleep apnea syndrome should be indisputable considered for the treatment [2]. Again, this item would be indicative for the clinicians who read this article while deciding the treatment options. Third, it is obvious that surgical or positive airway pressure treatment in sleep apnea patients would reduce the symptoms compared to nontreated patients with sleep apnea [2]. Therefore, we believe that groups had better be compared with a healthy control group. Last but not least, the patients had better be reevaluated by polysomnography tests for the clinical follow-up rather than a telephone questionnaire.

\section{CONFLICT OF INTEREST}

No potential conflict of interest relevant to this article was reported.

\section{REFERENCES}

1. Choi JH, Lee SH, Cho JH, Kim SW, Cho KS, Koo SK, et al. Five-year subjective outcomes of obstructive sleep apnea surgery: a multi-institutional study. Clin Exp Otorhinolaryngol. 2015 Dec;8(4):370-5.

2. Stansbury RC, Strollo PJ. Clinical manifestations of sleep apnea. J Thorac Dis. 2015 Sep;7(9):E298-310.

\footnotetext{
- Received December 27, 2015

Accepted April 6, 2016

- Corresponding author: Ahmet Cemal Pazarlı

Departments of Chest Diseases, Elbistan State Hospital, Karaelbistan,

46300, Kahramanmaras, Turkey

Tel: +90-344-413-8001, Fax: +90-344-413-8008

E-mail: cpazarli@hotmail.com
}

Copyright $\odot 2016$ by Korean Society of Otorhinolaryngology-Head and Neck Surgery.

This is an open-access article distributed under the terms of the Creative Commons Attribution Non-Commercial License (http://creativecommons.org/licenses/by-nc/4.0)

which permits unrestricted non-commercial use, distribution, and reproduction in any medium, provided the original work is properly cited. 